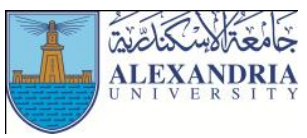

\title{
Effect of Using Qualitative Exercises on Electrical Activity of Muscles Operating in Long Jump Shooting in Handball
}

\author{
Ranya Mohamed Saeed Mahmoud ${ }^{1}$ \\ ${ }^{1}$ Lecturer, Department of Training Physical Sports, Faculty of Physical Education, Helwan University, Egypt
}

\begin{abstract}
:
The researcher conducted a study on purpose to recognize the effect of using qualitative exercises on the electrical activity of muscles working in the long jump shot skill in handball female players. The researcher used descriptive and experimental methods on a sample of (5) female players of the 1st class in handball. The electrical activity of muscles working in the long jump shot skill was measured in such female players ( 8 muscles in the upper limbs and 8 muscles in the lower limbs) before and after exposure to a program of qualitative exercises for such muscles. Measurement was taken by electromyography (EMG) and the program lasted (8) weeks by (3) units a week. The researcher concluded important results showing the positive effect of the qualitative exercises on loading muscular work of muscles working in the long jump shot in handball female players in the research sample.
\end{abstract}

Keywords: Electromyography, long jump shot in handball, qualitative exercises

\section{Research introduction and problem}

$\mathrm{T}$ The long jump shot aims to get rid of the defensive player to enable the shooter to shoot at the goal without hindrance and that is characterizing the long jump shot in handball thus we find it the most common type of shooting during the match as it is used in several positions and situations during the play (Munir,2004).

During the jump shot the muscular system of shoulder and arm was responsible for pushing the mass in the hand grip as well as protecting tissues around it (Rousanoglou,Noutsos,Bayios\& Boudolos,2014).

Muscles of trunk and legs produce more strength during jumping and as soon as reaching the nearest point in the jump the necessary amount of power is excreted together with taking the position of the whip movement by the shooting arm to produce the necessary power to release the ball (Brown,Loeb,2000).

When the strength. power or ability of coordination is decreasing in muscles and the implementation of the task is lowering than usual or required and the muscle could perform several mechanical functions and so the muscle could form the strength and power and by the time it could give a work produc (Brown,Loeb,2000) (Loeb,Brown,Cheng,1999).
So the electromyography (EMG) is considerably used to show the extent of muscle activation required to perform specific tasks and to study variability occurring in activating muscles as a result of training and performance and variations of the signal related to the capacity of the electrical activity outlining as a level of the activity quantitatively and leading to more understanding of activation of muscles through contributions of movement and concerned muscles during the jump shot in handball.(Gorostiaga,Granados,Ibanez\&Izquierdo,2005)(P ori,Bon\&Sibila,2005).

The qualitative exercises were those directed towards muscles concerned with performance that their dynamic direction should be in conformity with the motor path of skills performed (Mohammed,2015).

Training on exercises of performance corresponding to the skill movements by using muscles working in the required performance had an effective impact on developing and improving specific physical characteristics and skills (Fathi,2010).

Therefore. the researcher suggested that analyzing the electrical activity of muscles of the upper and lower limbs concerned with the performance of the long jump shot in handball by using electromyography (EMG) as a function of placing qualitative exercises for such muscles be important to upgrade the level of the skill. 


\section{Research objectives}

To place qualitative exercises for muscles working in the long jump shot skill in handball.

To identify the difference between the pre and postmeasurements of the research sample in the amount of electrical activity for muscles working in the long jump shot skill in handball.

\section{Research hypothesis}

There are significant differences between the pre and postmeasurements of the research sample in the amount of electrical activity of muscles working in the long jump shot skill in handball.

\section{Material and Methods}

Study Design:
The researcher used the descriptive and experimental methods as they were suitable for the nature of the current research and the experimental layout of one experimental group was followed and the pre and post-measurements were applied.

\section{Participants:}

It was selected intentionally from the 1 st class handball female players amounting (5) female players as each one of them performed 3 trials of long jump shot before and after applying the qualitative exercises and the best trial for each player was recorded that the number of trials under investigation was (20) by (5) trials before, (5) trials after applying the qualitative exercises for muscles of the upper limbs, (5) trials before, (5) trials after applying the qualitative exercises for muscles of the lower limbs.

The researcher computed coordination of the research sample in variables of age. height and weight. Table (1).

Table (1)

Arithmetic mean, standard deviation and skewness coefficient of the research sample in variables of (age. height and weight) $(n=5)$

\begin{tabular}{|c|c|c|c|c|}
\hline Variables & Units & $\mathrm{X}^{-}$ & SD & Skewness coefficient \\
\hline Age & Yr. & 21.14 & 0.44 & 0.96 \\
\hline Height & $\mathrm{cm}$ & 167.71 & 2.69 & 3.00 \\
\hline Weight & $\mathrm{kg}$ & 62.71 & 4.13 & 1.96 \\
\hline
\end{tabular}

\section{Experimental Procedures:}

\section{Research scopes:}

\section{I- The geographical scope:}

The pre and post-measurements of the electrical activity of muscles working in the long jump shot skill in handball was conducted and the proposed qualitative exercises were applied on the court of handball at Faculty of Physical Education for Girls. Jazira.

\section{II- Time zone:}

1- Pilot study on $1 / 1 / 2015$.

2- Pre-measurement on 4/1/2015.

3- The main experiment to apply the qualitative exercises in the period from Monday $5 / 1 / 2015$ to Saturday 28/2/2015

4- The post-measurement on 1/3/2015.

\section{Means and tools of collecting data:}

\section{Tools and equipment:}

Medical balance, restameter, multiple weights iron bar, dumbbells of multiple weights, sand sacs of multiple weights, medical balls of multiple weights, barriers, divided boxes, pinches, handballs, hoops, ropes, jacket of weights, rubber ropes, electromyography (Electrode configuration, Skin preparation).

Surveying references resulted in outlining the following muscles:

III- Muscles of the upper limbs concerned with performing the whip shot in handball:

The biceps brachia, the triceps brachia, the deltoid, the pectoralis major, serratus anterior, flexor of the wrist, brachioradialis and trapezius.

(Hamdy,2011)(Shima'a,2013)(AbdelRahman,2005)(Essa mAl-

Din,2011)(Mohammed,2015)(AbdelRahman,2015)(Balius ,2011)(Escamilla\&Andrews,2009)(Lippert,2011).

IV- Muscles of the lower limbs concerning with performing the long jump shot in handball:

The biceps femoris, gluteus maximus, quadriceps femorisrectus femoris, quadriceps femoris- vastus medialis, tibialis anterior, gastrocnemius-lateral part, gastrocnemiusmedialpart. (Shima'a, 2013) (Mohammed, 2015) (Bonnel, 1991) (Lippert, 2011) (Soderberg \& Cook, 983). 
a) Building the program:

1- The period of the program would be (8) weeks.

2- The number of training units in the program would be (24) by (3) units a week.

3- The unit time would be (60) min. divided as follows:

- Warming up would be (5) min.

- The qualitative exercises related to the skill under investigation would be (50) $\mathrm{min}$.
- Calming down would be (5) min.

4- Total time of the program would be (1440) $\mathrm{min}$.

5 - Load intensity used in the program would be from $(65 \%$ to $90 \%$ ).

\section{Presentation and discussion of results}

\section{I- Results:}

Table (2)

Significance of differences between the pre and post-measurements of the research sample in loading work of muscles (area) of the upper limbs operating in the long jump shot skill in handball $(n=5)$

\begin{tabular}{|c|c|c|c|c|c|c|}
\hline No. & Muscles & Units & Pre-measurement $X^{-}$ & $\begin{array}{c}\text { Post-measurement } \\
X^{-}\end{array}$ & Differences $X^{-}$ & $Z_{\text {value }}$ \\
\hline 1 & The biceps brachia & Uvs & 601.8 & 1083.4 & 481.6 & $18.83^{*}$ \\
\hline 2 & The triceps brachia & Uvs & 903.8 & 1403.4 & 499.6 & $13.33^{*}$ \\
\hline 3 & The deltoid anterior & Uvs & 1018.2 & 1721 & 702.8 & $* 6.52$ \\
\hline 4 & The pectoralis major & Uvs & 1143.2 & 1720.4 & 577.2 & $6.25^{*}$ \\
\hline 5 & The serratus anterior & Uvs & 735.2 & 1304.6 & 569.4 & $19.76^{*}$ \\
\hline 6 & Flexor of the wrist & Uvs & 703.8 & 1275.8 & 572 & $9.31^{*}$ \\
\hline 7 & Brachioradialis & Uvs & 840 & 4294.8 & 454.8 & $8.38^{*}$ \\
\hline 8 & Trapezius & Uvs & 3670.2 & 4086.6 & 416.4 & $4.58^{*}$ \\
\hline
\end{tabular}

Tabulated $(\mathrm{Z})$ value at $(0.05)$ level $=0.708$

Table (3)

Percentage of improvement (rate of variation) in values of the post-measurements for the pre-measurements of the research sample in electrical activity of muscles of the upper limbs operating in the long jump shot skill in handball $(n=5)$

\begin{tabular}{|c|c|c|c|c|c|c|}
\hline No. & Muscles & Units & Pre-measurement $X^{-}$ & $\begin{array}{c}\text { Post-measurement } \\
X^{-}\end{array}$ & Differences $X^{-}$ & Rate of improvement \% \\
\hline 1 & The biceps brachia & Uvs & 59 & 69 & 10 & 16.9 \\
\hline 2 & The triceps brachia & Uvs & 74.8 & 83.2 & 8.4 & 11.2 \\
\hline 3 & The deltoid anterior & Uvs & 65.8 & 70.8 & 5 & 7.6 \\
\hline 4 & The pectoralis major & Uvs & 60.4 & 64.9 & 4.5 & 7.4 \\
\hline 5 & The serratus anterior & Uvs & 89.4 & 111.8 & 22.4 & 25.1 \\
\hline 6 & Flexor of the wrist & Uvs & 70.7 & 77.9 & 7.2 & 10.2 \\
\hline 7 & Brachioradialis & Uvs & 72.9 & 79.6 & 6.7 & 9.2 \\
\hline 8 & Trapezius & Uvs & 56.8 & 59.5 & 2.7 & 4.8 \\
\hline
\end{tabular}

Tabulated $(\mathrm{Z})$ value at $(0.05)$ level $=0.708$ 
Table (4)

Significance of differences between the pre and post-measurements of the research sample in loading work of muscles (area) of the lower limbs operating in the long jump shot skill in handball $(n=5)$

\begin{tabular}{|c|c|c|c|c|c|c|}
\hline No. & Muscles & Units & $\begin{array}{c}\text { Pre-measurement } \\
X^{-}\end{array}$ & $\begin{array}{c}\text { Post-measurement } \\
X^{-}\end{array}$ & Differences $X^{-}$ & $Z$ Zvalue \\
\hline 1 & The biceps femoris & Uvs & 965.6 & 1401 & 435.4 & $10.84 *$ \\
\hline 2 & Gluteus maximus & Uvs & 1125.8 & 1433 & 307.2 & $6.87 *$ \\
\hline 3 & Quadriceps femoris - rectus femoris & Uvs & 851.6 & 1318.6 & 467 & $4.85^{*}$ \\
\hline 4 & Quadriceps femoris-vastus lateralis & Uvs & 912 & 1290.2 & 378.2 & $9.075^{*}$ \\
\hline 5 & Quadriceps femoris-vastus medialis & Uvs & 779.2 & 1138 & 358.8 & $8.80^{*}$ \\
\hline 6 & Tibialis anterior & Uvs & 1400.2 & 1258.6 & 483.4 & $6.02 *$ \\
\hline 7 & Gastrocnemius -lateral part & Uvs & 1060 & 1551.4 & 491.4 & $3.90^{*}$ \\
\hline 8 & Gastrocnemius-medial part & Uvs & 777.2 & 1217.2 & 440 & $11.89 *$ \\
\hline
\end{tabular}

Tabulated $(\mathrm{Z})$ value at $(0.05)$ level $=0.708$

Table (5)

Percentages of rates of variation (improvement) in values of the post-measurements for the pre-measurements of the research sample in the electrical activity of muscles of the lower limbs in the long jump shot skill in handball $(n=5)$

\begin{tabular}{|c|c|c|c|c|c|c|}
\hline No. & Muscles & Units & $\begin{array}{c}\text { Pre-measurement } \\
X^{-}\end{array}$ & $\begin{array}{c}\text { Post-measurement } \\
X^{-}\end{array}$ & $\begin{array}{c}\text { Differences } \\
X^{-}\end{array}$ & $\begin{array}{c}\text { Rate of } \\
\text { improvement } \%\end{array}$ \\
\hline 1 & The biceps femoris & Uvs & 70.9 & 77.5 & 6.6 & 9.3 \\
\hline 2 & Gluteus maximus & Uvs & 63.5 & 67.2 & 3.7 & 5.8 \\
\hline 3 & Quadriceps femoris - rectus femoris & Uvs & 61.7 & 64.4 & 2.6 & 4.2 \\
\hline 4 & Quadriceps femoris-vastus lateralis & Uvs & 67.8 & 73.2 & 5.4 & 7.9 \\
\hline 5 & Quadriceps femoris-vastus medialis & Uvs & 66.8 & 71.9 & 5.1 & 7.6 \\
\hline 6 & Tibialis anterior & Uvs & 62.9 & 66.1 & 3.2 & 5.1 \\
\hline 7 & Gastrocnemius -lateral part & Uvs & 60.9 & 63.1 & 2.2 & 3.6 \\
\hline 8 & Gastrocnemius-medial part & Uvs & 71.1 & 80.8 & 8.9 & 12.5 \\
\hline
\end{tabular}

Tabulated $(\mathrm{Z})$ value at $(0.05)$ level $=0.708$

\section{II- Discussion:}

Data in Table (2) show that there are significant differences between the pre and post-measurements of loading work of muscles (area) of the upper limbs operating in the long jump shot skill in handball in favor of the post-measurement in all muscles taking part in the performance. The researcher related that to the qualitative exercises applied to female players in the research sample. Such exercises could have a positive effect on loading the muscular work in the post-measurement for the same in the pre-measurement.

Also the results in Table (2) illustrate that the highest significance of difference between the pre and postmeasurements is for (the biceps brachia, the triceps brachia and the serratus anterior).

Data in Table (3) clarify that the percentage of improvement of the post- measurements for the premeasurements of the research sample is improved and it ranges between $(4.8 \%$ and $25.1 \%)$. The highest percentage of improvement of muscles is for the serratus anterior, the biceps brachia and the triceps brachia. The researcher suggested that such muscles got the highest significance of difference and the highest percentage of improvement may be for the reason that such muscles had the highest activity during the performance and the greatest burden of the requirements of performance of the shot skill in handball falls on them.

The biceps brachia helps move the elbow joint to achieve the maximum swing for the shooting arm to stabilize the joint prior to throwing towards the goal. Also it helps move the joint forward to increase the velocity of the throwing arm leading to stabilize the shoulder together with the main function of this muscle is to bend the elbow and the shoulder joint (Soderberg,1983). 
The triceps brachia extends the shooting arm forward and it abduces the ball off the trunk as possible to get benefit from the velocity and angle.

The serratus anterior fixes blade bone in its place to enable the deltoid to raise the muscle to more than 900 (AbdelRahman,2015).

This agreed with the results of Amin A.A.(Amin,1990), AbdelRahman\&Mohammed.(AbdelRahman,2015) who indicated to the relative importance of those muscles while shooting in handball.

The researcher attributed this positive variation in the electrical activity of muscles of the upper limbs to the proposed qualitative exercises for the research sample as the exercises focused precisely on muscles concerned with the performance through their function in the same motor path of the skill and that agreed with Mohammed Said Suliman that this type of exercises represented the maximum degree of specialization in improving the performance quantitatively, qualitatively and timely according to the momentary uses of muscles or set of muscles within the skill performance. Also such exercises could be used to operate and to build the body in line with skill requirements as well as developing and improving the correct performance of skills.

Data in Table (4) show that there are significant differences between the pre and post-measurements of loading the work of muscles (area) of the lower limbs operating in the long jump shot skill in handball in favor of the post-measurement in all muscles taking part in the performance. The researcher related that to the qualitative exercises applied to female players of the research sample as those exercises were characterized by multiplication and diversity and definitely targeted muscles of the lower limbs concerned with the long jump shot performance as the researcher identified tiny details of the skill together with outlining muscles operating and direction of the muscular work of the skill and hence, exercises were established by using the same set of operating muscles.

Data in Table (5) illustrate improving percentages of the post-measurements for the pre-measurements of the research sample. The percentages of improvement range from $(3.6 \%$ to $12.5 \%)$ and the highest percentage is for gastrocnemius - medial part and the biceps femoris.

When performing the long jump shot the left foot is raised from the ground bending at the end of takeoff and the right foot is raised to the outside (for gastrocnemius-lateral part) bending trying to maintain the dynamic balance of the body when the trunk inclined backward to the left where the gastrocnemius -lateral part and the quadriceps femoris-vastus medialis extend the knee joint and the instep and the biceps femoris contracts the knee joint and contribute to extend the thigh and the gluteus maximus raises the trunk and fixes the pelvis on the femur within the flight phase and when releasing the ball the left foot which was in the back due to the takeoff, proceeds to take a step forward to be ready for landing.

The researcher attributed this improvement occurred in the amount of electrical activity of muscles of the lower limbs to the nervous system that has sent considerable nerve signals to feed more number of muscular fibers to take part in muscular contraction leading to increase the electrical activity of muscles, moreover, the research sample benefited from returns of improving muscles operating in the long jump shot skill in handball.

That agreed with the study of Zachariah Anwar (Zachariah,2015) and the study of Mohammed S.S(Mohammed,2015) indicated to the significant effect of exercises directed to muscles operating in dynamic skills in swimming and handball.

The researcher suggested that the quantitative output of significance of differences were suitable and expressed the period of time of the proposed training program to train female players of the research sample.

Overall the researcher related the noticeable improvement in the electrical activity of muscles operating in the long jump shot skill to the increase in loading work of muscles during performing the skill which has been targeted by developing via the proposed qualitative exercises where it was considered that they should be in line with the dynamic model of the skill in respect of posture, the range of movement and contractions prevailed for muscle sets operating and participated in the performance as well as dynamic kinetic composition and course of time during the skill performance of the skill under investigation.

From the abovementioned presentation the researcher suggested that the previous results achieved the validity of the research hypothesis stating "there are significant differences between the pre and post-measurements of the research sample in the amount of electrical activity of muscles operating in the long jump shot skill in handball".

\section{Conclusions}

In the light of the research objectives and hypothesis and in limits of the sample and method used and on the basis of the results achieved, the following conclusions were drawn:

1- The proposed qualitative exercises had a positive effect on the amount of electrical activity of muscles of the upper 
and lower limbs operating in the long jump shot skill of the research sample.

2- Using readings of electromyography (EMG) to study the muscular work led to identify precisely the muscular work load of muscles operating in the long jump shot skill in handball before and after applying the program of qualitative exercises.

\section{Recommendations}

On the basis of the research results and conclusions, the researcher recommended the following:

1- Fundamentals of the proposed training program of qualitative exercises under investigation should be used during training handball players.

2- Considering training muscles operating in the long jump shot skill through applying more qualitative exercises within the training units.

3- Handball female players should be taken into consideration through conducting scientific studies to upgrade their levels.

4- Electromyography should be used to study the work of muscles in handball in other skills.

5- More studies should be conducted to set qualitative exercises according to requirements of the muscular work of handball skills.

\section{References}

\section{Arabic references:}

1- Abdel Rahman A.(2005):Principles of Descriptive and Functional Anatomy. 1st Ed. Book Publication Center.

2- Amin A.A. (1990, December). Description and Dynamic Analysis of the Jump Forward Shot through Two Performance Techniques. Scientific Book in Handball. 1st Year. vol.2.Egyptian Handball Federation,2,30-44.

3- Amr S.M.(2004):Theoretical treatments of some biomechanical variables as a basis to apply a qualitative preparation exercises program for young triple jumpers. Ph.D. Thesis (unpublished) Faculty of Physical Education, Minya University.

4- Essam Al-Din M.(2011):Kinematics and Biomechanics between Theory and Application. Al-Wafa'a Publication House, Alex.

5- Fathi A.H.(2010):Modern Practical Training in Handball. Horus International Publication Est.Alex
6- Gamal M.A.(1984). Drawing a mechanical apparatus of ball thrower as a mean to direct biomechanical stimuli for the movement shot skill in football. 5th Conference Proceedings.Faculty of Physical Education for Boys, Helwan University,69-84.

7- Hamdy A.(2011). Exercises of Muscular Strength and Operating Muscles. 1st Ed., Book Publication Center.

8- Heba R.L\& Ranya M.S(2014,November):The level of performance of the Egyptian National Team in comparison with top teams in 2013 World Handball Championship. International Journal of Sports Sciences and Arts, Faculty of Physical Education for Girls, Helwan University.

9- Kamal D.(ED)(1998):Physiological Principles of Handball Training, Theories - Applications. Book Publication Center.

10- Kamal D.(2002):Measurements, Evaluation and Analysis of the Game in Handball, Theories and Applications. 1st Ed. Book Publication Center.

11- Mohammed J.B.(ED)(2014):Essential Principles of Measurement of Electrical Activity of Muscles. 1st Part, Knowledge Inst. Alex.

12- Mohammed S.S.(2015):A qualitative complex training program in the light of electrical activity of muscles and its effect on the level of performance of the high jump shot skill in handball. Ph.D. Thesis (unpublished), Faculty of Physical Education for Boys, Alex. University.

13- Munir G.I.(1994):Handball for All. 4th Ed. Arab Thought House.

14- Munir G.I.(2004):Handball for All. Arab Thought House.

15- Shima'a F.S.(2013):Biomechanical changes associated with the jump shot skill performance after developing muscular power in handball female players. Ph.D. Thesis (unpublished), Faculty of Physical Education for Girls, Helwan University.

16- Yasser M.H.(2014):Comprehensive Preparation in Handball .

17- Zachariah A.A.(2015).Analysis of electrical activity of some muscles operating during swimming of young back crawl stroke swimmers. Ph. D. Thesis (unpublished), Faculty of Physical Education for Boys, Alex. University.

\section{Foreign references:}

18- AbdelRahman A.\& Mohamed Z.(2015, July):Electromyography Analysis of Selected Upper 
Extremity Muscles During Jump Throwing in Handball, American Journal of Sports Science,79-84.

19- Balius R.C.\&Pacheco L.\& Gutierrez JA.(2011):Rectus Abdominal Muscle injuries in elite handball Players,management and rehabilitation,Open access Journal of sports medicine, 2:69-73.

20- Bayios I.A\& Boudolos K.D.(1998):Accuracy and throwing velocity in Handball. 16 International Symposium on biomechanics in sports. KonstanzGermany,55-58.

21- Bonnel F.(1991):les Muscles de La Racine du membre supérieur (Muscles of The root of the upper limb). In: Bonnel F, Chevrel Jp, Qutrequin G. editors. Anatomie Clinique. Paris: Springer- Verlag,52-66

22- Brown I.E\& Loeb GE. A.(2000):reductionist approach to creating and using Neuromusculoskeletal models. New York:springer.

23-Escamilla RF\&Andrews JR.(2009):Shoulder Muscle recruitment patterns and related biomechanics during upper extremity sports. Sports Med,39,569-590.

24-Gorostiaga EM,Granados C,Ibanez J.\& Izquierdo M.(2005):Differences in Physical fitness and throwing velocity among elite and amateur male handball players. International Journal of sports Medicine,26,225-232.
25-Lippert Ls.(2011):Clinical Kinesiology and anatomy. Fifth ed. united States of America. F.A. Davis Company.

26-Loeb GE.,Brown IE\&Cheng EJ.(1999):A hierarchical Foundation for models of sensorimotor control. Exp Brain Res, 126,1-18.

27-Pori P., Bon M.\& Sibila M.(2005):jump Shot performance in team handball. A Kinematic Model evaluated on the basis of expert modeling. International Journal of fundamental and Applied Kinesiology,37,4049.

28-Rousanoglou EN., Noutsos Ks., Bayios IA.\& Boudolos KD.(2014):Electromyography Activation Patterns during Handball Throwing by Experts and Novices. J. Athl. Enhancement,3,1-8.

29-Soderberg GL.\& Cook TM.(1983):An electromyography analysis of quadriceps femoris muscle setting and straight leg raising Physical Therapy,63,14341438 .

30-Visnapuu M, Jurimae T.(2007):Handgrip Strength and hand dimensions in young handball and basketball players. J. Strength Cond Res,21,923-929.

31- Zajac FE, Neptune RR\& Kautz SA.(2002):Biomechanics and muscle Coordination of human walking.Part I:introduction to concepts, power transfer, dynamics and Simulations. Gait \& 